\title{
Causes and effects of lack of sleep in hospitalized children
}

\author{
Carlos R. Vecchi, M.D. ${ }^{a}$
}

\begin{abstract}
Sleep is a key function that takes up one third of our lives. Sleep deprivation may lead to physical and psychological disorders in the short and long term.

Hospitalization, regardless of its cause, does not favor good enough and restorative sleep. It is affected by both external (light, noise) and internal (procedures, drugs, care) factors.

The intensive care unit is the place where falling asleep and maintaining sleep is more difficult. This is in addition to disease severity and the characteristics of its structure and functioning. A poor sleep quantity or quality may trigger an acute confusional state, which often affects hospitalized children, known as delirium. Promoting a joint effort among all sectors of the hospital setting targeted at protecting sleep as much as possible is the required task.

Key words: circadian rhythms, setting, delirium, sleep.

http:/ / dx.doi.org/10.5546/ aap.2020.eng.e143
\end{abstract}

To cite: Vecchi CR. Causes and effects of lack of sleep in hospitalized children. Arch Argent Pediatr 2020;118(2):e143-e147.

"The morning is just starting and I wake up; I have been unconscious and oblivious to what was going on around me. I was restoring my energy while my brain worked tirelessly processing what I had done during the day and in prior days."

a. Argentine Society of Pediatric Neurology (Sociedad Argentina de Neurología Infantil, SANI).

E-mail address:

Carlos R. Vecchi, M.D.: carlosvecchi1@gmail.com

Funding:

None.

Conflict of interest:

None.

Received: 1-17-2019

Accepted: 8-25-2019

\section{INTRODUCTION}

Disease and its severity, in addition to the external factors intrinsic to the setting, disrupt the day and night balance and alter sleep continuity and structure. Many times, disorders extend over time and result in a lack of sleep. It has been pointed out that, in healthy individuals, sleep deprivation with 4 hours of sleep or less may lead to a reduced cognitive performance. ${ }^{2}$
It is surprising that teams and institutions that safeguard patients underestimate sleep, even though it is known for its healing power. A survey administered in the United States to 626 pediatricians revealed that a large number of them did not ask about sleep and its deviations. Also, $74 \%$ asked one or no questions about sleep when their patients were adolescents (42\% did so when they were preschoolers and schoolchildren). Training time devoted to sleep in pediatric residency programs amounted to 4.8 hours. ${ }^{2,3}$ Mindel reported that the most commonly used bibliography in pediatrics discussed sleep only in $1.8 \%$ of its content. ${ }^{4}$

Our primary objective was to depict the negative impact of the hospital setting on sleep among hospitalized pediatric patients, describe its causes and effects, and attempt to provide measures aimed at prevention and management. In order to interpret the results of sleep deprivation on physical and mental aspects, it is necessary to consider, first of all, the critical features of sleep by age.,4, Then, the environmental factors that disrupt sleep in hospitalized pediatric patients, especially at the intensive care unit are described.

\section{SLEEP AND CIRCADIAN RHYTHMS}

In the first 2 years of life, human beings sleep 10000 hours and are awake for 7000 hours. At this stage, the brain develops at its fastest rate. ${ }^{7,8}$ For newborn infants, sleep takes up 16-18 hours daily, and there is no difference between day and night sleep. The day/night sleep ratio changes from 0.93 at 1 week old to $0.15-0.20$ at 12 months old. $5,8,9$ 
In our life, we go through three different stages: wakefulness, non-rapid eye movement (NREM) sleep, and rapid eye movement (REM) sleep. After the first 8 months of life, broadly speaking, sleep goes through the drowsiness, light sleep, and deep sleep stages, known as N1, $\mathrm{N} 2$, and N3, respectively. Stage N1 accounts for up to $5 \%$ of all night. This is followed by light sleep (N2), which repeats throughout the night and, during childhood, is close to $50 \%$ of total sleep time. Lastly, stage N3 (deep sleep) is preeminent during childhood $(20 \%)$.

Slow, deep sleep is a biological marker of the so-called sleep pressure, because it increases depending on the time spent awake during the day. ${ }^{2,5,9,10}$ Deep sleep or stage N3 is closely related to explicit and declarative memory; and many neuroendocrine functions take place during it, such as growth hormone release.

Between 60 and 90 minutes after sleep initiation, the first REM sleep occurs; it is usually brief and includes rapid eye movements accompanied by total muscle atony (only the eyes and the diaphragm move). Such loss of muscle tone is the responsibility of the brainstem nuclei. ${ }^{5,9}$ Then, REM sleep alternates with NREM sleep and, every 90 minutes, it returns and its percentage increases toward dawn $(25 \%$ of total sleep time).

According to Hobson, the different stages of sleep would be a "physiological psychotic state of mind. Sleep plays the role of a librarian who, at the end of the day, classifies and puts every book that has been consulted back in order". ${ }^{11}$

\section{CIRCADIAN RHYTHM}

\section{(CIRCA `ABOUT’'DIES 'DAY’)}

In the $18^{\text {th }}$ century, Jean-Jacques d'Ortous de Mairan observed the plant Mimosa pudica, whose leaves opened when exposed to the sun and closed at dusk. The monk and astronomer placed it in a dark place, away from the light, and once again, its leaves opened during the day and closed during the night. This evidenced that the plant had its own endogenous rhythm. ${ }^{14}$

A few years ago, German researchers studied bee colonies that had a memory of time because they looked for food every day, at the same time. The bees were moved to New York by plane, but looked for their food at the same time that they did in Germany. ${ }^{15}$

The Earth rotates 360 degrees every 24 hours, with regular periods between light and darkness. For millions of years, live organisms have experienced their existence in a rhythmic manner, with the help of their biological clock.

Circadian rhythms are those that take place around 24 hours (cortisol, temperature, cardiovascular and pulmonary function, etc.). An infradian rhythm is that with a frequency of less than 24 hours (hormone release, REM and NREM periods every 40 minutes in newborn infants and every 90 minutes in adults). An ultradian rhythm has longer periods (menstrual cycle, hibernation in certain animals). ${ }^{12}$ Every bodily function is a response to a rhythm. The orchestra conductor is the suprachiasmatic nucleus (SCN), located in the hypothalamus and formed by a small group of neurons (20 000-50 000). Its synaptic endings develop during the day and activate during the night. ${ }^{12,16}$

There is inter-individual variability given that, in some people, the biological clock starts every 24.3 or 24.4 hours. Such delay forces to reset it, and this occurs according to the environmental guidelines provided by the setting. In case of disconnection between the biological clock and external guidelines (light, physical activity, eating), the internal control (SCN) prevails. ${ }^{16}$ Light is the main external synchronizer. After impacting the retina, light travels through a retinohypothalamic tract toward its final destination, the SCN. The light/darkness cycle is critical in order to respect the wakefulness and sleep schedule. "Time is born in the eyes, everybody knows that" (Julio Cortázar). ${ }^{15}$

Day and night rhythms are different, and the coordination between the SCN and the peripheral clocks working in all cells through countless numbers of genes helps to match the central clock to the peripheral one. Such synchrony is established through humoral and/or neural pathways.

If the wakefulness/sleep cycle is not respected, a misalignment occurs, and peripheral clocks work at different rates, as the instruments of an orchestra that has lost its harmony. Balance restoration is critical.

In such synchronizing and chronobiotic effort, it is worth noting the presence of melatonin, the hormone of darkness that is synthesized from tryptophan and secreted by the pineal gland. Melatonin is strongly inhibited by light, and its levels during the day are null. Melatonin secretion starts around 7 p.m. (dim light melatonin onset, DLMO). Together with temperature, it is a marker of circadian phase. ${ }^{2,12,15}$

Sleep is closely related to temperature. It 
is more intense when temperature reaches its lowest levels, between 2 and 3 p.m. (nap time) and between 4 and 5 a.m. Sleep follows body temperature like a shadow follows its physical form. ${ }^{2,5}$ It rises in the morning and, between 6 and 9 p.m., wakefulness enhances closely related to the temperature rise.

\section{THE HOSPITAL SETTING}

At this point, we can discuss sleep in patients admitted to a hospital's general ward. Certainly, environmental precautions to ensure a normal sleep inside the hospital are far from friendly. Alarms, cell-phones, visitors, patient handoffs, gurneys, and medical trolleys, among other things, are real endemic noise factors. They are the most common cause of arousals and, therefore, sleep fragmentation. Their presence is invasive and results in a chain of physiological events that lead to cortical activation, with vasoconstriction, increased blood pressure, mydriasis, and a greater muscle tension, associated with a sympathetic discharge with adrenaline release. ${ }^{17}$

In general, noise exceeds the values recommended by the World Health Organization (25-30 decibels), although acoustics levels are unknown because they are not usually measured. Friedman did a polysomnography in 22 patients for $24-48$ hours and found that $17 \%$ of arousals and microarousals were caused by noise. ${ }^{18,19}$

Another environmental factor that is closely and negatively related to sleep is excess light. The level of light outdoors is approximately 10000 lux (lux = one lumen per square meter). ${ }^{20,21}$ On a full moon night, it reaches 0.25 lux and, in a room with a window, the value is 1000 lux. A surgical table has 2000 lux; a waiting room, 200 units; and lux values are even higher in locations where procedures are done.

The presence of 100 lux is enough to inhibit melatonin secretion. ${ }^{2,20}$ Excessive light during the night suppresses melatonin secretion, which is in charge of synchronizing central and peripheral rhythms. During the night, if luminance was measured, its intensity would be surprisingly high, because secondary sources from around the patient's bed are usually not assessed.

In the bibliography, the benefits of wearing an eye mask or earplugs as non-pharmacological measures on day or night sleep have been reported. Some reviews have shown that a single measure to reduce the use of light to acceptable levels improves sleep. ${ }^{22}$ Routine, structured controls conducted mechanically are questionably beneficial for the patient and a waste of useful time among the nursing staff. Interruptions during patient sleep force to restructure the schedule depending on each clinical situation. In addition, dyssomnia is not an unusual chronic sequela after hospital discharge.

\section{SLEEP AT THE INTENSIVE CARE UNIT}

Eckle claims that only a few attempts have been made to minimize chronodisruption in critically-ill patients, as if it was a minor problem. ${ }^{23}$ The presence of sleep disturbances is common in pediatric patients admitted to the intensive care unit. Its causes are multifactorial. ${ }^{2,20,24}$ Between $18 \%$ and $65 \%$ of children aged 2-18 years hospitalized in the critical care unit present with a clinical condition of acute confusional state, better known as delirium. In its acute form, and due to multiple factors, including a lack of sleep, this fluctuating process takes place, but it is not clearly understood. ${ }^{20,24}$

It is a complex process associated with a reduced alertness and impaired attention, accompanied with perceptual and cognitive alterations. ${ }^{12}$ The greater risk factors include age younger than 3 years, previous mental retardation, positive family history, emotional problems. ${ }^{25}$ Triggering factors include noise, lighting restriction during the day, absence of windows, opioids, propofol, steroids, and anticholinergic use. ${ }^{21,26}$ Fragmentation, a reduced total sleep time, the absence of slow, deep sleep and REM sleep, as well as a displacement toward daytime hours, are alterations that may also act as triggers. Their presence worsens patient course, prolongs their stay, and increases the risk for complications and mortality. 2,27,28

Sleep alterations are alarms that require a strict monitoring and, although attempted therapies have not been successful, an early diagnosis may shorten the length of delirium. ${ }^{28-30}$ It has been described as hyperactive, with aggression and irritability, or as hypoactive. It is not uncommon for patients to experience an alternating (mixed) form. Hyperactive delirium is clear. ${ }^{30}$ Hypoactive delirium, also known as acute apathy syndrome, shows negative symptoms (little mobility and lack of attention), and its diagnosis is more intricate. It is more common in children, and prognosis is worse. ${ }^{31}$

Therefore, some authors have recommended the involvement of pediatric psychiatry specialists in diagnosis and the use of structured assessment tools -although those used at present do not 
include data on sleep duration and quality. ${ }^{31,32}$ A cautious administration of sedatives for the management of delirium is the core recommendation, and its objective is to minimize their side effects. All sedatives cause untoward changes on sleep architecture because restorative sleep (N3) and REM sleep are reduced.

Anticholinergics, which are commonly used in ventilated patients, and benzodiazepines may facilitate the onset of delirium in adults and children. In critically-ill patients, benzodiazepines are an independent risk factor for delirium. ${ }^{26,33}$

The temporal relationship suggests causality and somehow supposes a contraindication to its use, although they are most commonly used as first-line drugs..$^{20,28,34}$ In adults, new agents, such as suvorexant (randomized, controlled study), would have a beneficial effect on the prevention of delirium. ${ }^{35}$

Lastly, melatonin levels are reduced in critically-ill patients, which opens up the expectations for its use, and it may prevent the evolutionary course toward delirium. Some studies have reported adequate results with melatonin or agonists. ${ }^{28,36}$

Inadequate light intensity and schedules, noise peaks at decibels higher than those recorded in any other part of the hospital, unavoidable surgical procedures, necessary sample collections (several times a day), bed baths, ongoing nurse controls, visitors, alarms and sensors, chatting and conversations during patient handoffs are all causes of sleep disruption.

Patel and, more recently, other authors have pointed out significant reduction changes in the rate of delirium with the implementation of non-pharmacological measures regarding excessive light use, noise reduction, rational night controls, necessary family contact, prevention of continuous staff changes, and environmental guidelines; all these measures tend to reduce anxiety levels. ${ }^{25}$

Finally, sleep assessment includes questionnaires, diaries, and actigraphy; however, it has been recognized that, in spite of difficulties in the performance and interpretation of polysomnography, it is still the gold standard to detect sleep alterations in a more accurate manner and tell the difference between normal and pathological sleep.

To a lesser extent, this is the case of prolonged electroencephalogram. Many times, sleepdeprived critically-ill patients who undergo severe processes, receive ventilation or have burn wounds show bioelectric characteristics that are different from those observed in normal sleep. For example, during wakefulness, slow delta band rhythms of $0.5-3$ cycles per second (cps) or theta band rhythms of 4-7 cps, which are typical of slow, paradoxical sleep, are observed. ${ }^{37}$ During wakefulness, the normal base rhythm is that of the alpha band, with rhythms of 9-12 cps. These findings question reliability. Anyhow, these are still recommended as assessment methods.

Insistence about clinical observation and the probable use of mass technology applications, whose scientific validation has yet to be tested, may be aspects to be discussed and probably implemented in the near future and in certain type of patients. ${ }^{38}$

Sleep in critically-ill patients is frequently interrupted due to several environmental factors, invasive procedures, nurse care, pain, drug administration, etc. Setting up the protection of sleep among all members of the health care team in the hospital setting, especially in the intensive care unit, is a shared responsibility.

What granted the Homo sapiens an advantage over all other animals and turned them into the masters of the planet was not our individual rationality, but our unparalleled ability to think together in large groups. $^{39}$

\section{REFERENCES}

1. Damasio A. El error de Descartes. Lisboa:Temas de Debate; 1994.

2. Drouot X, Quentin S. Sleep neurobiology and critical care illness. Crit Care Clin. 2015; 31(3):379-91.

3. Owens J. The practice of pediatric sleep medicine: results of a community survey. Pediatrics. 2001; 108(3):E51.

4. Mindell J, Moline M, Zendell S, Brown LW, et al. Pediatricians and sleep disorders: training and practice. Pediatrics. 1994; 94(2 Pt 1):194-200.

5. Mindel J, Owens J (eds.). Clinical guide to pediatric sleep: diagnosis and management of sleep problems. $3^{\text {rd }}$ ed. Philadelphia: Wolters Kluwer Press; 2015.

6. Killgore W. Effects of sleep deprivation on cognition. Prog Brain Res. 2010; 185:105-29.

7. Hill C, Hogan A, Karmiloff-Smith A. To sleep: perchance to enrich learning? Arch Dis Child. 2007; 92(7):637-43.

8. Pin Arboledas P, Lluch Rosello A. El sueño en el primer año de vida: ¿cómolo enfocamos? Rev Pediatr Aten Primaria. 2011; 13(Supl 20):101-11.

9. Ferber R. Introduction pediatric sleep disorders medicine. In: Ferber R, Kriger M (eds.). Principles and practice of sleep medicine in the child. Philadelphia: Saunders; 1995.Págs.1-6.

10. Anders T, Avi S, Apparadey V. Normal sleep in neonates and children. In: Ferber R, Kriger M (eds.). Principles and practice of sleep medicine in the child. Philadelphia: Saunders; 1995.Págs.7-18.

11. Hobson J. Sleep is of the brain, by the brain and for the brain. Nature. 2005; 437(7063):1254-6.

12. Billings $M$, Watson N. Circadian dysrhythmias in the Intensive care unit. Crit Care Clin. 2015; 31(3):393-402. 
13. Krause A, Simon E, Mander B, Greer S, et.al. The sleepdeprived human brain. Nature Rev Neurosci. 2017; 18(7):404-18.

14. Dement W. History of sleep physiology and medicine. In: Kriger M, RothT, Dement W (eds.). Principles and practice of sleep medicine. $2^{\text {nd }}$ ed. Philadephia: Saunders; 1994. Pages 3-16.

15. Golombek D. La máquina del tiempo. In: Golombek D. Cronobiología humana: ritmos y relojes biológicos en la salud y en la enfermedad. Buenos Aires: Universidad Nacional de Quilmes; 2002.Págs.19-29.

16. McKenna H, Van der Horst GTJ, Reiss I, Martin D. Clinical chronobiology: a timely consideration in critical care medicine. Crit Care. 2018; 22(1):124.

17. Fillary J, Chaplin H, Jones H, Thompson A, et al. Noise at night in hospital general wards: a mapping of the literature. Br J Nurs. 2015; 24(10):535-40.

18. Tembo A, Parker V. Factors that impact on sleep in intensive care patients. Intensive Crit Care Nurs. 2009; 25(6):314-22.

19. Darbyshire J, Young J. An investigation of sound levels on intensive care units with reference at $\mathrm{WHO}$ guidelines. Crit Care. 2013; 17(5):R187.

20. Traube C, Silver G, Gerber L, Kaur S, et al. Delirium and Mortality in Critically 111 Children: Epidemiology and Outcomes of Pediatric Delirium. Crit Care Med. 2017; 45(5):891-8.

21. Engwall M, Fridh I, Johansson L, Bergbom I, et al. Lighting, sleep and circadian rhythm: An intervention study in the intensive care unit. Intensive Crit Care Nurs. 2015; 31(6):325-35.

22. Hu R, Jiang X, Chen J, Zeng Z, et al. Non-pharmacological intervention for sleep promotion in the intensive care unit. Cochrane Database Syst Rev. 2015; 6(10):CD008808.

23. Eckle T. Delirium - A dysfunctional circadian rhythm. Int J Anesthesiol Res. 2016; 4(1e):1-3.

24. Patel J, Baldwin J, Bunting P, Laha S. The effect of a multicomponent multidisciplinary bundle of interventions on sleep and delirium in medical and surgical intensive care patients. Anaesthesia. 2014; 69(6):540-9.

25. Van Tuijt S, Van Cauterrer YJ, Pithard T, Engel M, et al. Management of pediatric delirium illness: a practical update. Minerva Anestesiol. 2015; 81(3):333-41.
26. Madden K, Hussain K, Tasker R. Anticolinergic Medication Burdern in Pediatric Prolonged Critical Illness: A Potentially Modifiable Risk Factor for Delirium. Pediatr Crit Care Med. 2018; 19(10):917-24.

27. Kudchadkar S, Aljohani O, Punjabi N. Sleep of critically ill children in the pediatric intensive care: a systematic review. Sleep Med Rev. 2014; 18(2)103-10.

28. Calandriello A, Tylka J, Patwari Pl. Sleep and delirium in pediatric critical Illness. What is the relationship? Med Sci (Basel). 2018; 6(4):E90.

29. Arora R, Cunningham C. Losing over delirium. Crit Care Med. 2018; 46(6):1036-8.

30. Fitzgerald J, Adamis D, Trzepacz P, O’Reagan N, et al. Delirium: a disturbance of circadian integrity? Med Hypotheses. 2013; 81(4):568-76.

31. Schenveld J, Strik J. Hypoactive delirium is more appropriately named as Acute apathy syndrome. Crit Care Med. 2018; 16(10):1561-2.

32. Barnes S, Grados M. Kudchadkar SR. Child psychiatry engagement in the management of delirium in critically Ill children. Crit Care Res Pract. 2018; 2018:9135618.

33. Zaal IJ, Devlin JW, Hazelbag M, Klein Klouwenberg P, et al. Benzodiazepine-associated delirium in critically ill adults. Intensive Care Med. 2015; 41(12);2130-7.

34. Patel A, Bell M, Traube C. Delirium in Pediatric Critical Care. Pediatr Clin Noth Am. 2017; 64(5):1117-32.

35. Azuma K, Takaesu Y, Soeda H, Iguchi A, et al. Ability of suvorexant to prevent delirium in patients in the intensive care unit: a randomized controlled trial. Acute Med Surg. 2018; 5(4):362-8.

36. Mody K, Kaur S, Mauer E, Gerber L, et al. Benzodiazepines and development of delirium in critically ill children: estimating the causal effect. Crit Care Med. 2018;46(9):148691.

37. KudchadkarS, Yaster M, Punjabi A, QuanS, etal. Temporal Characteristics of the sleep EEG power spectrum in critically Ill children. J Clin Sleep Med. 2015; 11(12):1449-54.

38. Khosla S, Deak M, Gault D, Goldstein C, et al. Consumer sleep technology: an American Academy of Sleep Medicine Position Statement. J Clin Sleep Med. 2018; 14(5):877-80.

39. Harari YN. Ignorancia. In: Harari YN. 21 Lecciones para el siglo XXI. Buenos Aires: Debate; 2018.Page 242. 